This is an open access article under the CC BY-NC-ND license (https://creativecommons.org/licenses/by-nc-nd/3.0/) Issue III, November 2020

ISSN 2707-9481

ISBN 978-601-323-207-2

https://doi.org/10.31643/2020.038

\section{Serikhan T. Shormanov}

RSE at REM «Republican Research Institute for Labor Protection of the Ministry of Labor and Social Protection of the Population of the Republic of Kazakhstan»»

Republic of Kazakhstan, Email: nauka@rniiot.kz https://orcid.org/0000-0003-0170-3990
Anar B. Ibraeva

RSE at REM «Republican Research Institute for Labor Protection of the Ministry of Labor and Social Protection of the Population of the Republic of Kazakhstan»

Republic of Kazakhstan, Email: nauka@rniiot.kz https://orcid.org/0000-0002-9056-2423

\title{
A set of measures to reduce the level of industrial injuries based on occupational risk management
}

\begin{abstract}
In this article, the authors have identified the main causes of industrial injuries, which will allow implementing an effective set of measures aimed at reducing and preventing accidents at work. The analysis of the causes and circumstances of industrial injuries is carried out on the basis of the classifier of the causes of an accident associated with work. The determination of the optimal corrective measures to reduce industrial injuries is carried out on the basis of their choice from the classifier of measures in accordance with the efficiency criteria. For each case of industrial injuries, a set of measures is drawn up to improve the quality of life and health of the company's employees. The article was prepared based on the results of research work on the topic: "Development of scientific and methodological foundations for ensuring safe work in priority sectors of the economy of the Republic of Kazakhstan" (IRN 61897 / PCF-MLSPP RK-OT-20).
\end{abstract}

Keywords: labor protection, occupational risk, industrial injuries, a set of measures.

Cite this article as: Shormanov S. T., Ibraeva A. B. (2020). Kompleks meropriyatiy po snizheniyu urovnya proizvodstvennogo travmatizma na osnove upravleniya professional'nymi riskami [A set of measures to reduce the level of industrial injuries based on occupational risk management]. Challenges of Science. Issue III, p.: 235-239. (In Russian). https://doi.org/10.31643/2020.038

\section{Серикхан Турсынханович Шорманов}

РГП на ПХВ «Республиканский научно-исследовательский институт по охране труда Министерства труда и социальной защиты населения Республики Казахстан» Республика Казахстан, Email: nauka@rniiot.kz https://orcid.org/0000-0003-0170-3990

\section{Анар Боранбаевна Ибраева}

РГП на ПХВ «Республиканский научно-исследовательский институт по охране труда Министерства труда и социальной защиты населения Республики Казахстан» Республика Казахстан, Email: nauka@rniiot.kz https://orcid.org/0000-0002-9056-2423

\section{Комплекс мероприятий по снижению уровня производственного травматизма на основе управления профессиональными рисками}

\footnotetext{
Абстракт. В данной статье авторами выделены основные причины производственного травматизма, которые позволят реализовать эффективный комплекс мероприятий, направленный на снижение и
} 
предотвращение несчастных случаев на производстве. Анализ причин и обстоятельств производственного травматизма проводится на основе классификатора причин несчастного случая, связанного с трудовой деятельностью. Определение оптимальных корректирующих мер по снижению производственного травматизма проводится на основе их выбора из классификатора мер в соответствии с критериями эффективности. По каждому случаю производственного травматизма составляется комплекс мероприятий для повышения качества жизни и здоровья работников предприятия. Статья подготовлена по результатам научно-исследовательских работ по теме: «Разработка научно-методических основ обеспечения безопасного труда в приоритетных секторах экономики Республики Казахстан» (ИРН 61897/ПЦФ-МТСЗН РК-ОТ-20).

Ключевые слова: охрана труда, профессиональный риск, производственный травматизм, комплекс мероприятий.

\section{Введение}

Снижение производственного травматизма является приоритетной задачей системы управления охраной труда, важным элементом которой является оценка профессионального риска.

В 2020 году РГП на ПХВ «Республиканский научно-исследовательский институт по охране труда Министерства труда и социальной защиты населения Республики Казахстан»рамках выполнения научно-технической программы на тему «Разработка научно-методических основ обеспечения безопасного труда в приоритетных секторах экономики Республики Казахстан» разработал комплекс мероприятий по охране труда на основе управления профессиональными рисками по снижению производственного травматизма на предприятиях.

Производственный травматизм обусловлен воздействием одной или совокупностью нескольких причин, для снижения которого необходимо провести причинно-следственный анализ производственного травматизма, и уже на основе его результатов определить эффективные меры по его снижению возможно посредством проведения мер, направленных на устранение причин производственного травматизма [1].

При разработке методики планирования мер по снижению производственного травматизма на основе управления профессиональными рисками разработчики руководствовались требованиями отечественного законодательства, аналогичными требованиям МОТ, а также Директиве 89/391, на которой основаны трудовые нормы европейских стран. Международная практика определяет корректирующие меры в соответствии с установленной иерархией исключить и заменить, технический контроль, мера осведомленности, информация, средства индивидуальной защиты и требует обязательного проведения превентивных мер в случае выявления профессионального риска по результатам его оценки. Методика описана в виде руководства к определению корректирующих мер для управления профессиональными рисками и предусматривает пошаговый алгоритм действий, направленных на определение наиболее эффективных мер по снижению производственного травматизма с учетом причинно-следственной связи.

\section{Результаты}

Планирование комплекса мероприятий по охране труда на основе управления профессиональных рисков по снижению производственного травматизма включает в себя:

1) Сбор информации, данных, систематизация о случае и/или случаях производственного травматизма. По результатам собирается первичная информация для анализа причин и обстоятельств производственного травматизма;

2) Анализ причин и обстоятельств производственного травматизма, результатов оценки профессиональных рисков в соответствии с порядком. По результатам определяется причина или совокупность причин, которые привели к случаю производственного травматизма; 
3) Определение оптимальных корректирующих мер по снижению производственного травматизма на основе их выбора из классификатора мер в соответствии с критериями эффективности. Проводится в соответствии с порядком, указанным в разделе 5 настоящей Методики. По результатам разрабатывается комплекс мер.

Анализ причин и обстоятельств производственного травматизма проводится на основе классификатора причин несчастного случая, связанного с трудовой деятельностью, согласно которому производственный травматизм может произойти в результате 24 различных причин.

Все указанные в классификаторе причины производственного травматизма разделены на следующие три группь:

1) организационные причины: несвоевременное или некачественное проведение инструктажей и обучения по охране труда работающих, отсутствие инструкций по охране труда; недостаточный контроль за выполнением требований охраны труда работающими, неудовлетворительное содержание рабочего места, недостатки в организации групповых работ, в обеспечении рабочих спецодеждой и другими средствами индивидуальной защиты (СИЗ); использование техники, инструментов не по назначению, нарушение режима труда и отдыха, технологического процесса.

2) технические причины: конструктивные недостатки машин, механизмов, инструментов, приспособлений или их неисправность; отсутствие, несовершенство, неисправность оградительных, блокировочных, вентиляционных устройств; зануления или заземления электроустановок; подтекание ядовитых жидкостей, газов и т.д.

3) санитарно- гигиенические причины: повышенное содержание в воздухе вредных веществ, высокий уровень шума, вибрации, излучения, нерациональное освещение, антисанитарное состояние рабочих мест и бытовых помещений, неблагоприятные природно-климатические условия или микроклимат в помещениях, несоблюдение правил личной гигиены и др [2].

Определение оптимальных корректирующих мер по снижению производственного травматизма проводится на основе их выбора из классификатора мер в соответствии с критериями эффективности.

Все указанные в классификаторе меры по снижению производственного травматизма разделены на три группы:

1) организационные меры: обучение производственного персонала, проведение инструктажей; организация кабинета, учебного класса, уголка; выдача спецодежды, спецобуви и средств индивидуальной защиты; внедрение систем контроля за использованием СИЗ; средств коллективной защиты на производственных объектах; распространение предупредительных надписей и знаков, плакатов.

2) технические меры: ремонтные работы; технические осмотры; установка предохранительных, защитных и сигнализирующих устройств (приспособлений); установка устройств заземления (зануления), изоляция проводов электросистем; замена устаревшего производственного оборудования на новое оборудование; замена опасного производственного оборудования на более безопасное (например, применение вакуумных выключателей вместо масляных, сухие разделки кабелей); ограждение движущихся частей механизмов, неизолированных токоведущих частей электрооборудований, установка стационарных вентиляций (приточно-вытяжных, приточных) в помещениях и на наружных установках по очистке воздуха и т.д.

3) санитарно-гигиенические меры: применять звукоизоляцию, звукопоглощение, демпфирование и глушители шума; замена вредных веществ и материалов безвредными или менее вредными; осуществить герметизацию и оборудования, источника загрязнения воздуха рабочей зоны; дозиметрический контроль; защитные меры от холода или вредных тепловых излучений; рационализировать технологические процессы, устраняющие образование пыли, паров и газов или удаляющие вредные вещества из технологического процесса и др.

По каждому случаю производственного травматизма с учетом причин и обстоятельств его возникновения производится выбор корректирующей меры аналогичного характера. По каждому 
случаю производственного травматизма составляется комплекс мероприятий по снижению производственного травматизма на основе управления профессиональными рисками. Профессиональные риски должны быть устранены и (если это невозможно) снижены путем принятия превентивных мер в порядке приоритетности согласно пяти уровней управления:

- меры по устранению профессионального риска, т.е. сведение его уровня к нулю.

- меры по замене опасного неопасным или менее опасным, т.е. сведение более высокого профессионального риска к меньшему.

- меры инженерного контроля, под которым понимаются технические средства, ограничивающие или предупреждающие возникновение несчастного случая на производстве. Приоритет должен отдаваться мерам коллективной защиты Примером таких мер является местная вытяжная вентиляция для контроля рисков от пыли или дыма.

- меры административного контроля или организащионные меры. Проведение таких мер предполагает, уменьшение или устранение профессионального риска путем соблюдения процедур или инструкций. Документация должна подчеркивать все шаги, которые необходимо предпринять, и средства контроля, которые необходимо использовать для безопасного осуществления деятельности.

- мерь по обеспечению средствами индивидуальной защчить (СИЗ). Выдача СИЗ рассматривается как мера, которая применяется только после проведения всех вышеуказанных мер, в случае невозможности устранения и/или снижения профессионального риска. Эффективность таких мер зависит от правильного выбора защитного снаряжения, его использования и обслуживания. Алгоритм методики представленного на рисунке 1.

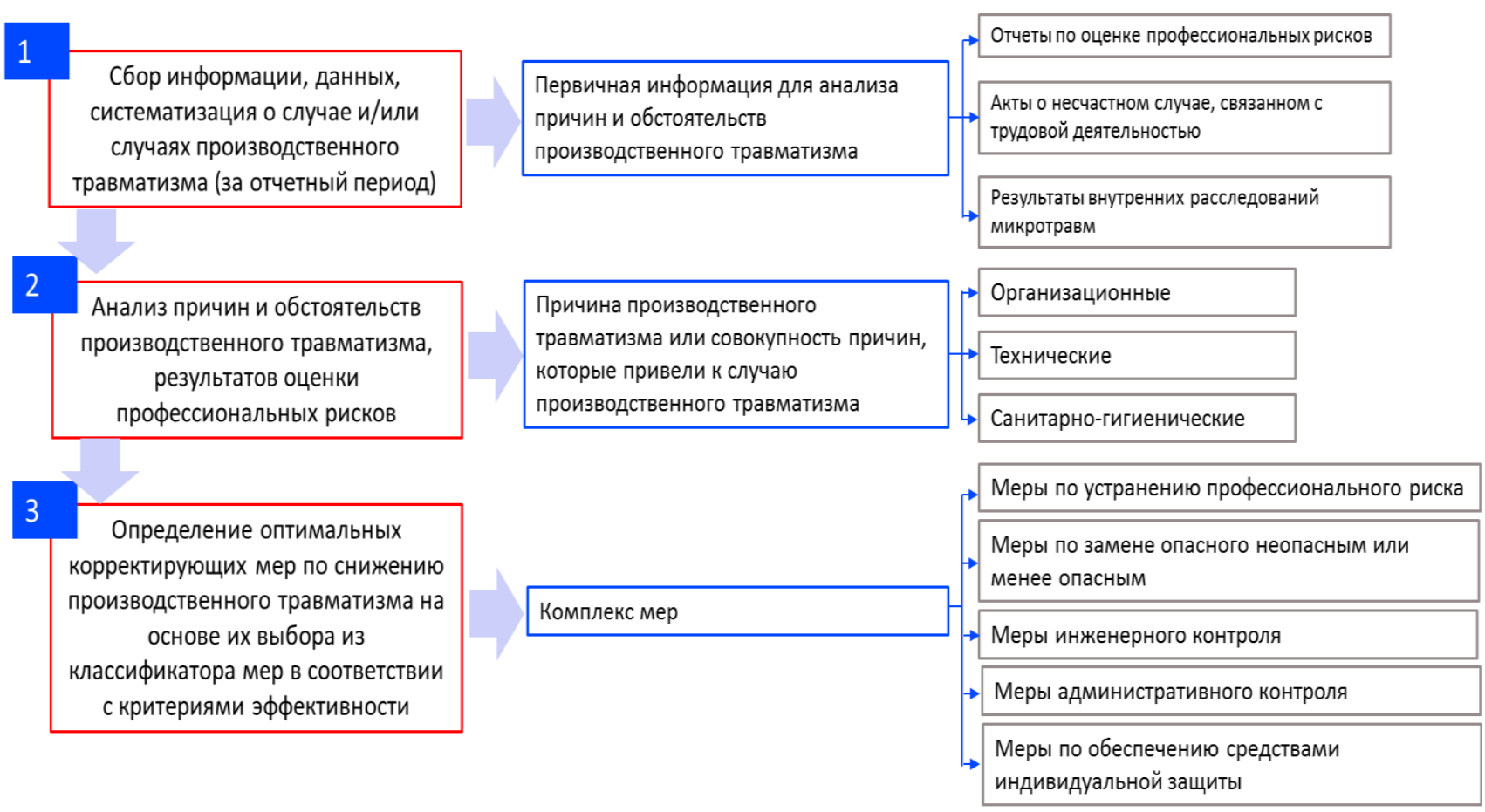

Рисунок 1 - Алгоритм формирования комплекса мероприятий по снижению уровня производственного травматизма на основе управления профессиональными рисками

Метод управления профессиональным риском (корректирующие меры) представляет собой последовательно выполняемую комбинацию различных вариантов мер, указанных в классификаторе мер. Между собой все меры, связаны с обучением рабочих, имеющим основополагающее значение для предотвращения и контроля профессиональных рисков.

Комплекс мероприятий по снижению производственного травматизма на основе управления профессиональными рисками должен быть утвержден руководителем предприятия. 


\section{Выводы}

Данная методика ориентирована на предприятия среднего и малого бизнеса и микропредприятия различных ВЭД и форм собственности, внедряющие СУОТ, согласно требованиям действующего законодательства, и направлена на оказание методической помощи при анализе причин производственного травматизма и разработке корректирующих мер по его снижению.

Внедрена система добровольного декларирования соответствия условий безопасности труда работодателей требованиям законодательства, предусматривающая снятие административных барьеров и снижение затрат работодателей, в первую очередь, представителей малого и среднего бизнеса. Сформирована система отраслевых норм по безопасности и охране труда, санитарных правил и гигиенических нормативов, государственная и ведомственная система учета несчастных случаев на производстве и профессиональных заболеваний и статистической отчетности.[3]

Научная гипотеза данной методики предполагает, что производственный травматизм обусловлен воздействием одной или совокупностью причин. Поэтому его снижение возможно посредством проведения мер, направленных на устранение причин производственного травматизма, источник возникновения профессионального риска. Для этого необходимо провести причинноследственный анализ производственного травматизма, и уже на основе его результатов определить эффективные меры по его снижению.

Ссылка на данную статью: Шорманов С. Т., Ибраева А. Б. (2020) Комплекс мероприятий по снижению уровня производственного травматизма на основе управления профессиональными рисками. Материалы Международной практической интернет-конференции «Актуальные проблемы науки» [Challenges of Science]. Выпуск III, стр. 235-239. https://doi.org/10.31643/2020.038

\section{Литературы}

[1] Приказ Министра здравоохранения и социального развития Республики, Казахстан от 28 декабря 2015 года № 1055 «Об утверждении форм по оформлению материалов расследования несчастных случаев, связанных с трудовой деятельностью».

[2] Тыналина Г.Б., Скрипченко Н.В., Тыналин А.О. Обзор методов и методик, применяемых для оценки эффективности систем управления охраной труда/ Вестник КазАТК № 3 (114), 2020.- С 94-100

[3] Шорманов, С (2019) Қазақстан Республикасындағы еңбек қауіпсіздігі мен еңбекті корғау жүйесінің жай-күйі. «Ғылымның өзекті мәселелері» - Халықаралық практикалық интернет- конференция материалдары / Materials of International Practical Internet Conference "Challenges of Science". ISBN 978-601-323- 144-0. Басылым II, 2019. Бет: 64-67. https://doi.org/10.31643/2019.011

\section{References}

[1] Prikaz Ministra zdravookhraneniya i sotsial'nogo razvitiya Respubliki, Kazakhstan ot 28 dekabrya [] Order of the Minister of Health and Social Development of the Republic of Kazakhstan dated December 28] 2015 goda № 1055 «Ob utverzhdenii form po oformleniyu materialov rassledovaniya neschastnykh sluchayev, svyazannykh s trudovoy deyatel'nost'yu». (In Russian).

[2] Tynalina G.B., Skripchenko N.V., Tynalin A.O. Obzor metodov i metodik, primenyayemykh dlya otsenki effektivnosti sistem upravleniya okhranoy truda [Review of methods and techniques used to assess the effectiveness of OSH management systems] / Vestnik KazATK № 3 (114), 2020.- S 94-100. (In Russian).

[3] Shormanov, S (2019) Qazaqstan Respwblikkasındağ1 eñbek qawipsizdigi men eñbekti qorğaw jüyesiniñ jay-küyi [The state of the system of occupational safety and health in the Republic of Kazakhstan]. «Ğılımnıñ özekti mäseleleri» - Xalıqaralıq praktikkalıq ïnternet- konferencïya materïaldarı / Materials of International Practical Internet Conference "Challenges of Science”. ISBN 978-601-323- 144-0. Bas1lım II, 2019. Bet: 64-67. https://doi.org/10.31643/2019.011. (In Kazakh). 